\title{
Instrumental Texture Profile Analysis (TPA) of Cucumber Fruit as Influenced by Its Part and Maturity Stage
}

\author{
Oderhowho Nyorere, Hilary Uguru* \\ Agricultural and Bio-Environmental Engineering Technology Department, School of Engineering, Delta State Polytechnic, Ozoro, Nigeria
}

Email address:

erobo2011@gmail.com (H. Uguru)

${ }^{*}$ Corresponding author

To cite this article:

Oderhowho Nyorere, Hilary Uguru. Instrumental Texture Profile Analysis (TPA) of Cucumber Fruit as Influenced by Its Part and Maturity Stage. American Journal of Engineering and Technology Management. Vol. 3, No. 4, 2018, pp. 54-60. doi: 10.11648/j.ajetm.20180304.11

Received: September 15, 2018; Accepted: September 27, 2018; Published: October 24, 2018

\begin{abstract}
Instrumental texture profile analysis (TPA) of Nandini cucumber fruit, was measured as a function of its parts (stalk, mid and blossom), and maturity stages. These textural parameters; hardness, springiness, adhesiveness, gumminess, stringiness, fracturability, and chewiness of the fruit were measured; over a course of four maturity stages, 6, 9, 12 and 15 Days after Peak Anthesis (DAPA). The texture profile analysis was done by using the Warner-Bratzler shear force (WBS) method, and the results showed that maturity stage and fruit part significantly $(\mathrm{P} \leq 0.05)$ influenced all the textural parameters evaluated. Over the course of maturation, all the parameters investigated were found to increase. During maturation, the stalk, mid and blossom hardness increased by 25,26 and 32\% respectively; springiness increased by $6.4,7.7$ and $6.2 \%$ in the stalk, mid and blossom; gumminess increased by $57.7,57.4$ and $42.2 \%$ in the stalk, mid and blossom; chewiness increased by 60.5 , 63.1 and $47 \%$ in the stalk, mid and blossom; fracturability increased from 89.13 to $118.29,82.76$ to 110.7 and 62.28 to $90.12 \mathrm{~N}$ in the stalk, mid and blossom; adhesiveness increased from 9.14 to $13.2,8.49$ to 12.27 and 7.15 to 9.83 Ns in the stalk, mid and blossom; lastly, stringiness increased from 20.05 to $21.61,19.46$ to 20.81 and 19.06 to $19.79 \mathrm{~mm}$ in the stalk, mid and blossom. The results showed significant correlation of all the parameters investigated with maturation and fruit part.
\end{abstract}

Keywords: Texture Profile Analysis, Cucumber Fruit, Maturity Stage

\section{Introduction}

Cucumber (Cucumis sativus L.) belongs to the Cucurbitaceae family, with an outstanding source of minerals, essential amino acids and vitamins [1]. Cucumber fruit has several pharmacological potentials, such as; antioxidant, antiwrinkle, antimicrobial, antidiabetic, and hypolipidemic in addition, the copper content of cucumber seeds helps in stimulating the process of neurotransmission which helps to improves the overall brain coordination. Recently, Nandini cucumber is one the popular cultivars of cucumber cultivated in many parts of Nigeria, and neighbouring countries due to its substantial growth and production potentials [2-5].

Texture is a sensory feature and is composed of several textural properties including mechanical (hardness, chewiness and viscosity), geometrical (particle size and shape) and chemical (moisture and fat content) characteristics [6], and it is one of the least well described of the many organoleptic food attributes of concern to food engineers. Knowledge of textural properties is important for stakeholders in the food value chain including producers, postharvest handlers, processors, marketers and consumers. For fresh foods such as fruit and vegetable, firmness is widely used as indices of readiness to harvest (maturity), to meet requirements for long term handling, storage and acceptability by the consumer. For processed foods, textural properties are important for the control of processing operations such as heating, frying and drying to attain desired quality attributes of the end product [7-8]. Fruit texture depends on these anatomical features, tissue layers and cell size; which result in a combination of different subphenotypes, for example, firmness, mealiness, gumminess etc. Firmness is determined mainly by the skin cell size and the shape of the underlying pericarp cell layers of the fruit [9]; and it is related to the cell wall structure and architectural changes occurring during the fruit development and ripening 
phases [10-11].

Texture profile analysis (TPA) is the measurement and description of the textural properties of food items, and it is measured either by a trained sensory panel (organoleptic) or using specialized equipment (instrumental). Instrumental TPA is one of the methods to determine food texture by simulating the repeated biting or chewing of the food. Traditionally, in most techniques for the evaluation of fruit mechanical properties, the fruit is assumed as a continuum material in which the mechanical properties essentially do not depend on the spatial scale. However, fruits consist of different tissues, and their macroscopic mechanical behaviour depends on several microscopic properties [12]. The textural properties of foods, which govern the appropriate selection of the method and device used for their testing, are divided into:

i. Basic properties; which are brittleness (fracturability), hardness (firmness), cohesiveness and elasticity (springiness) and adhesiveness.

ii. Secondary (derivative) properties; which are chewiness and gumminess $[7,13]$.

Pervious researchers have worked on the textural properties of many crops. For instance, [14] investigated the firmness of dates as a function of maturity, and reported that at 103 days after pollination, the force required to penetrate the dates was $186 \times 104 \mathrm{~Pa}$, which decreased to $53.6 \times 104$ $\mathrm{Pa}$ at 152 days after pollination. Reference [15] analyzed 14 regional varieties of apples from Portugal, and observed that most of the apples had higher springiness values in the axial orientation than in the radial orientation. Six commercial apple cultivars (Golden Delicious, Stark Delicious, Renetta, Annurca, Granny Smith, and Emperor) were studied by [16] to discriminate among the cultivars and the different levels of merceological quality for their mechanical and texture characteristics, using instrumental and sensory methods; they found out that Annurca and Granny Smith cultivars showed the highest values for almost all the instrumental and sensory parameters measured. So far, there no reported literature on the textural profile analysis of Nandini cucumber fruit, as affected by its maturity stage and fruit part (stalk, mid and blossom). Therefore, the present study was undertaken to determine some of the textural parameters (springiness, hardness, fracturability, stringiness, chewiness and gumminess) of the Nandini cucumber fruit

\section{Materials and Methods}

\subsection{Sample Preparation}

The Nandini cucumber fruits were harvested from the research farm of Delta State Polytechnic, Ozoro, Nigeria, over a course of four maturity stages, 6, 9, 12 and 15 Days after Peak Anthesis (DAPA). The cucumber fruits were selected at random on the basis of uniformity of shape, size, and freedom from diseases and pests attacks.

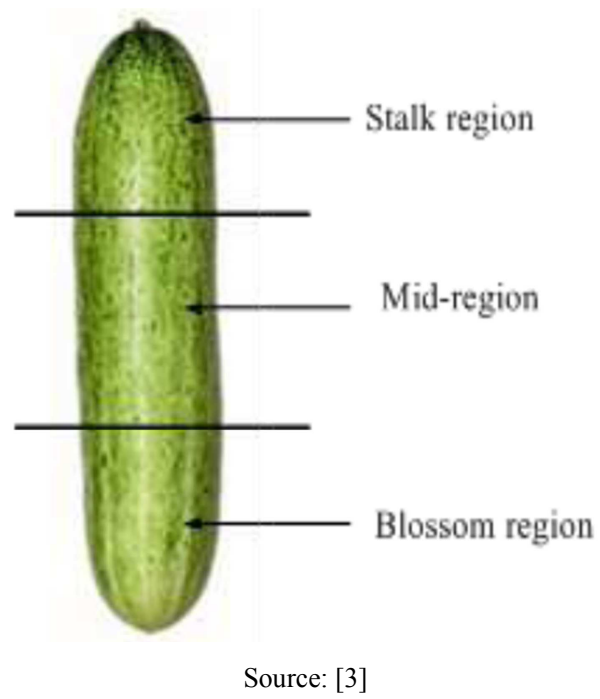

Figure 1. A cucumber fruit showing the three parts.

\subsection{Texture Profile Analysis (TPA)}

The TPA was performed on the intact fruits immediately after harvest with respect to the fruit's part as shown in Figure 1, using the Warner-Bratzler shear force (WBS) method, with the aid of the Universal Testing Machine (Testometric model, series 500-532) with accuracy of $0.001 \mathrm{~N}$. For each test, a single cucumber fruit was positioned horizontally in the machine, a test probe went into a position ( $50 \%$ of the original diameter of the fruit) in the fruit at a speed of $105 \mathrm{~mm} / \mathrm{min}$, and then returned to the point where pre-load was reached on the first cycle. It then waited for a short time which is supposed to represent the time between chews, before it went the second time. From the force-time graph of two cycles, the following attributes; hardness, springiness, adhesiveness, gumminess, stringiness, fracturability, and chewiness were determined automatically by the machine. The probe depth was set to $50 \%$ of each fruit's diameter; because at this range a possible fluctuation will not significantly affected the TPA parameters, as higher probe depth can cause some TPA parameters (hardness, gumminess and chewiness), to shift dramatically [17]. Ten fruits were tested individually and the average value recorded.

The hardness of a fruit is the force at maximum compression during first bite; cohesiveness is how the item holds together; springiness is the distance or length of compression cycle during the second bite (rate at which a deformed item reforms); adhesiveness is the rate at which item comes away from probe(instrumental) or roof of mouth/teeth (organoleptic); Fracturability is the initial force needed for a material to fracture; chewiness is the energy required to chew a solid food until it is ready for swallowing; stringiness is the distances food extends before it breaks away from compression plates; Gumminess is the energy required to disintegrate a semisolid food until it is ready to swallow. Popular terms used to describe gumminess are short, mealy, pasty and gummy $[7,18]$. 


\subsection{Statistical Analysis}

Data obtained from this study were subjected to variance analysis using SPSS 20.0 statistical software. The mean separation of parameters investigated was done by using Duncan's Multiple Range tests at 95\% confidence level.

\section{Results and Discussion}

The analyses of variance (ANOVA) result for the effect of fruit part and maturity stage on the seven textural parameters (hardness, springiness, adhesiveness, gumminess, stringiness, fracturability, and chewiness) investigated of Nandini cucumber fruit is presented in Table 1. As shown in Table 1, the fruit part and maturity stage significantly $(\mathrm{P}<0.05)$ influenced all the textural parameters investigated; while the interaction of fruit part and maturity stage only significantly $(\mathrm{P}<0.05)$ influenced the adhesiveness, gumminess, and chewiness of the fruit. In regards to the other parameters, the interaction of the fruit part and maturity period did not significantly influence them.

Table 1. Analysis of variance of effect of fruit part and maturity stage on the Textural parameters of Nandini cucumber fruit.

\begin{tabular}{|c|c|c|c|c|c|c|c|c|}
\hline Source & df & Hardness & Springiness & Gum & Chewiness & Stg & Frt & Adh \\
\hline$P$ & 2 & $3.13 \mathrm{E}-28^{*}$ & $2.03 \mathrm{E}-24 *$ & $3.72 \mathrm{E}-32 *$ & 7.09E-33* & $7.42 \mathrm{E}-10^{*}$ & $3.85 \mathrm{E}-07^{*}$ & $2.21 \mathrm{E}-23 *$ \\
\hline M & 3 & $1.59 \mathrm{E}-27 *$ & $3.85 \mathrm{E}-12 *$ & $4.79 \mathrm{E}-37 *$ & $1.11 \mathrm{E}-35^{*}$ & $1.06 \mathrm{E}-09 *$ & $1.01 \mathrm{E}-04 *$ & $1.24 \mathrm{E}-25^{*}$ \\
\hline $\mathrm{P} \times \mathrm{M}$ & 6 & $0.41819^{\mathrm{ns}}$ & $0.59323^{\mathrm{ns}}$ & $1.62 \mathrm{E}-18 *$ & $4.38 \mathrm{E}-18^{*}$ & $0.070261^{\mathrm{ns}}$ & $0.35453^{\text {ns }}$ & $2.48 \mathrm{E}-03 *$ \\
\hline
\end{tabular}

* =Significant on the level of $5 \%$; $\mathrm{ns}=$ non-significant; $\mathrm{P}=$ Cucumber part; $\mathrm{M}=$ maturity stage; Gum = Gumminess; Stg = Stringiness; Adh = Adhesiveness; Frt $=$ Fracturability

According to the data obtained from the research, there was significant increment in the hardness of the cucumber fruit as maturation progressed from 0 to 15 DAPA (Figure 2), which could be attributed to result of major changes that occurred in the fruit's structural tissues during maturation. Also, the results indicated that the strength of internal bounds (hardness) in the fruit was highest in the stalk part, than in the remaining two parts (mid and blossom), depicting different cellular structures across the cucumber fruit [3]. Similar results were obtained for three apple (Kim, Mutsu and Jonagold) varieties, where hardness ranged of 50.74 to 62.11 $\mathrm{N}$ [17]; while [19] reported that the hardness of four classes of Atrophy kernel increased with the increase in mass and size.

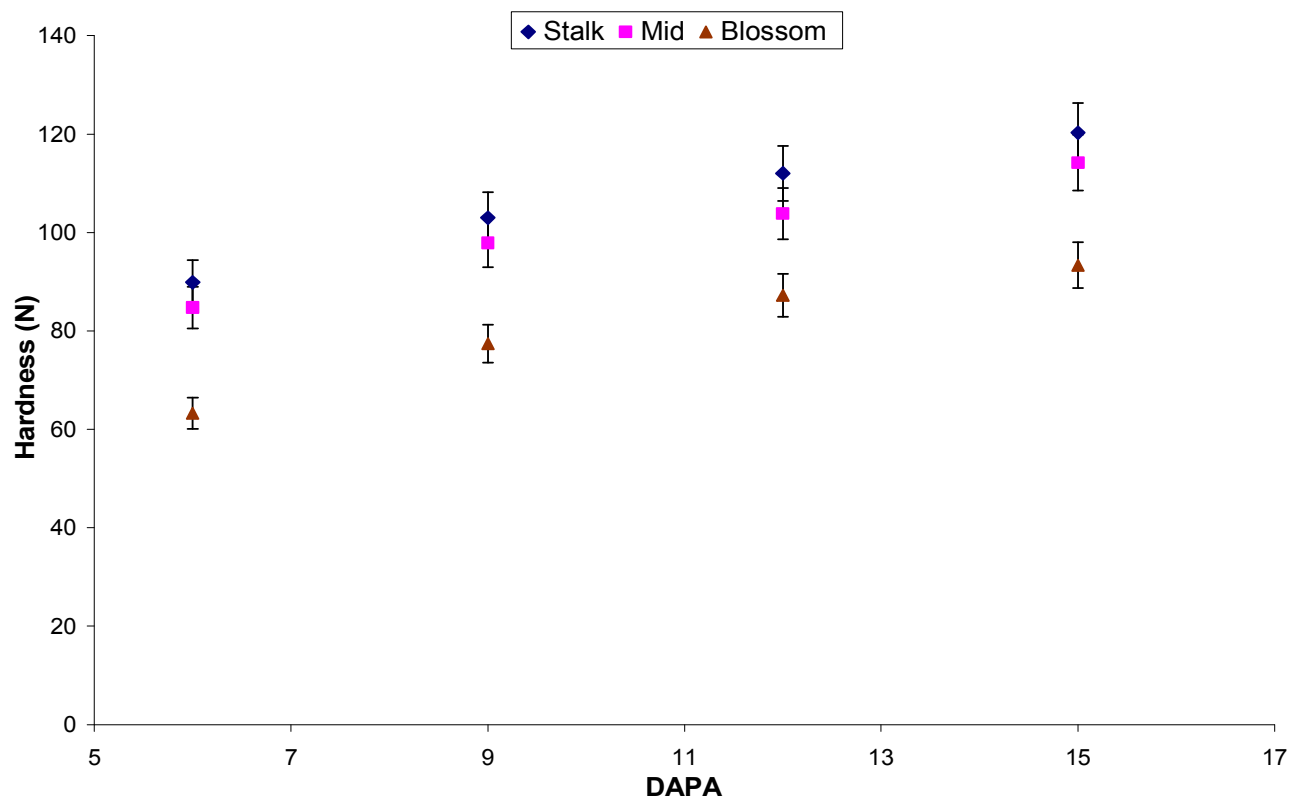

Figure 2. Effect of fruit part and maturity stage on the hardness of Nandini cucumber fruit.

As presented in Figure 3, the fruit's fracturability increased as maturation increases from 0 to 15 DAPA and was highest in the stalk part. From the data obtained, there were no significant differences in the fruit fracturability for the second, third, and fourth maturity stages, but significant differences occurred between the first and second maturity stages. With respect to the springiness of the cucumber fruit, it increased from the stalk to the blossom part of the fruit (Figure 4), which indicated high elasticity at the stalk part of the fruit, in relative to the other parts. These results were similar to earlier reports on apple fruit (Mutsu variety) where springiness was $1.36 \mathrm{~mm}$ in tangential orientation and 1.57 $\mathrm{mm}$ in radial orientation [17]. Comparing fruits originating from similar tissue structures (either inner or outer cortex), orientation usually had pronounced influence on its springiness. Also, relative importance of texture as a quality attribute varies among various types of fresh fruits, and it is greatest in firm, fleshy fruits such as apples and pears $[15,20]$. 


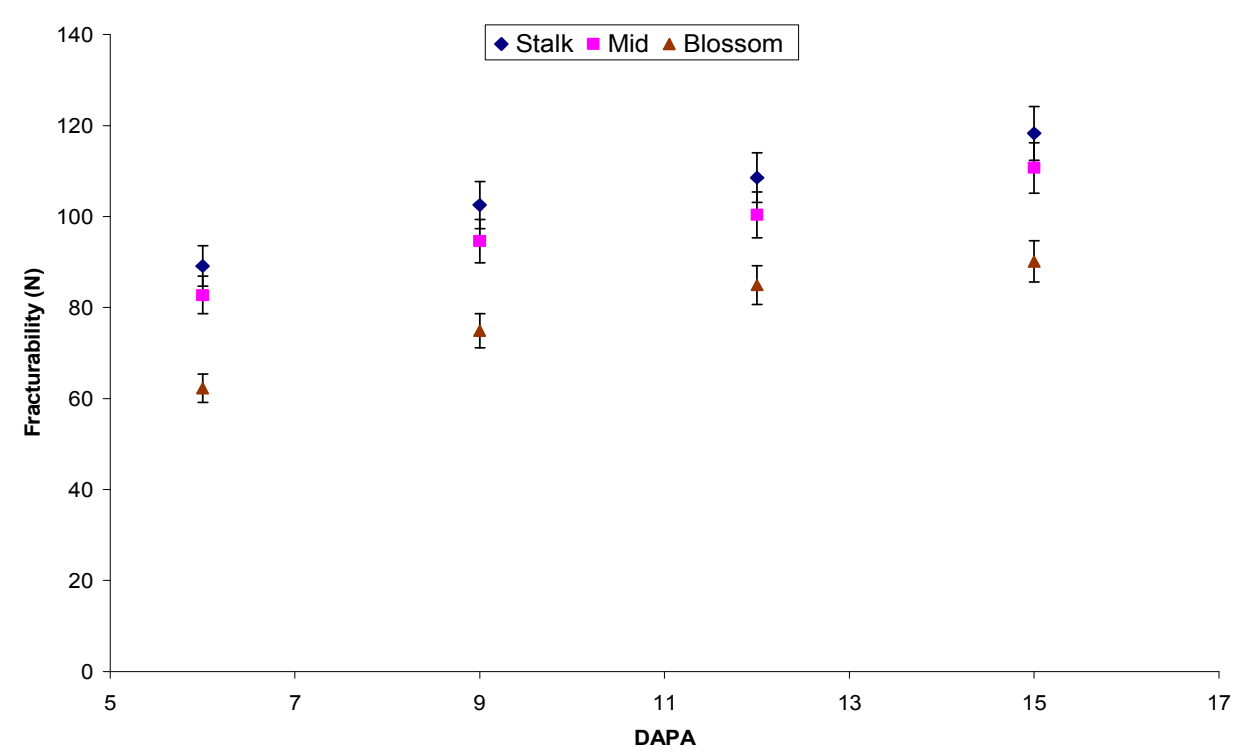

Figure 3. Effect of fruit part and maturity stage on the fracturability of Nandini cucumber fruit.

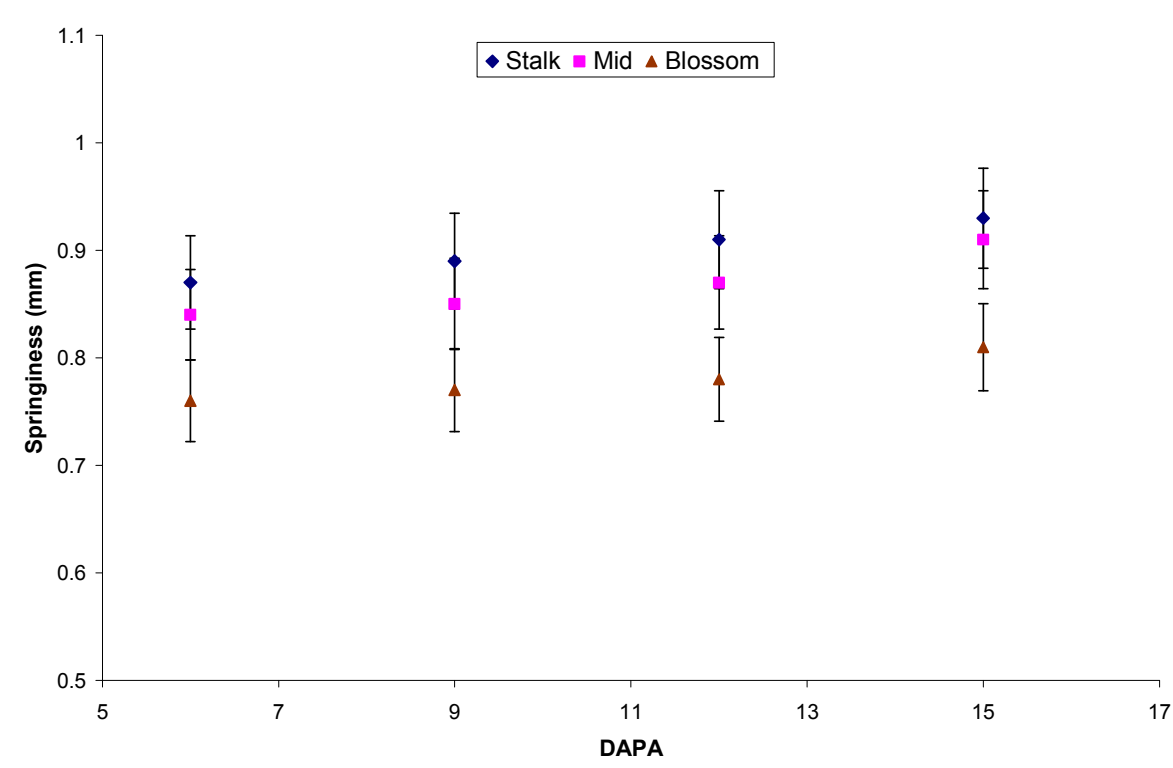

Figure 4. Effect of fruit part and maturity stage on the springiness of Nandini cucumber fruit.

In reference to the data obtained from the research, the blossom part had the lowest chewiness value than the mid and stalk parts (Figure 5). During maturation the fruit's chewiness increased by about $60 \%$ in the stalk, $63 \%$ in the mid and $47 \%$ in the blossom part. In addition, the lowest chewiness values were observed at the earliest stage of maturity (6 DAPA), which clearly proved the softness of the cucumber fruit at this stage; and can be linked to the chemical, enzymatic and structural tissue changes within the fruit during maturation [21].

In respect to the fruit's adhesiveness, the results indicated that the adhesive forces between the surface of the cucumber fruit, and other surface contacts decreased from the blossom part to the stalk part of the fruit. The results at the four maturity stages demonstrated an obvious difference in the values of adhesiveness in the three parts of the fruit (Figure 6). Considering gumminess, all the data obtained were relatively low, but were influenced by maturity stage and fruit part (Figure 7). The gumminess increased by about $57 \%$ in the stalk, $56 \%$ in the mid and $42 \%$ in the blossom part of the fruit.

The data obtained for the fruit's stringiness with respect to its maturity stage and part, shown significant difference (Figure 8). Textural properties of different dates' varieties as a function of mass and size were investigated by [22], and observed that hardness, resilience and chewiness increased exponentially with the decrease of water content, whereas cohesiveness, adhesiveness and springiness showed a peak at around $21.5 \%$ water content. 


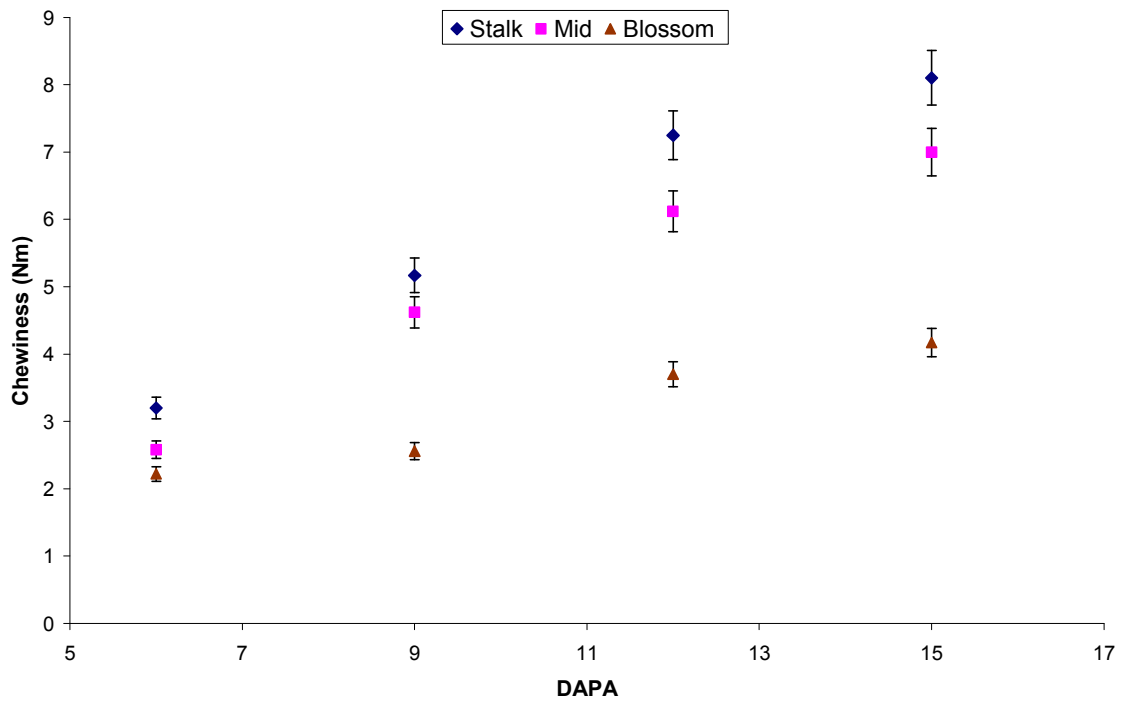

Figure 5. Effect of fruit part and maturity stage on the chewiness of Nandini cucumber fruit.

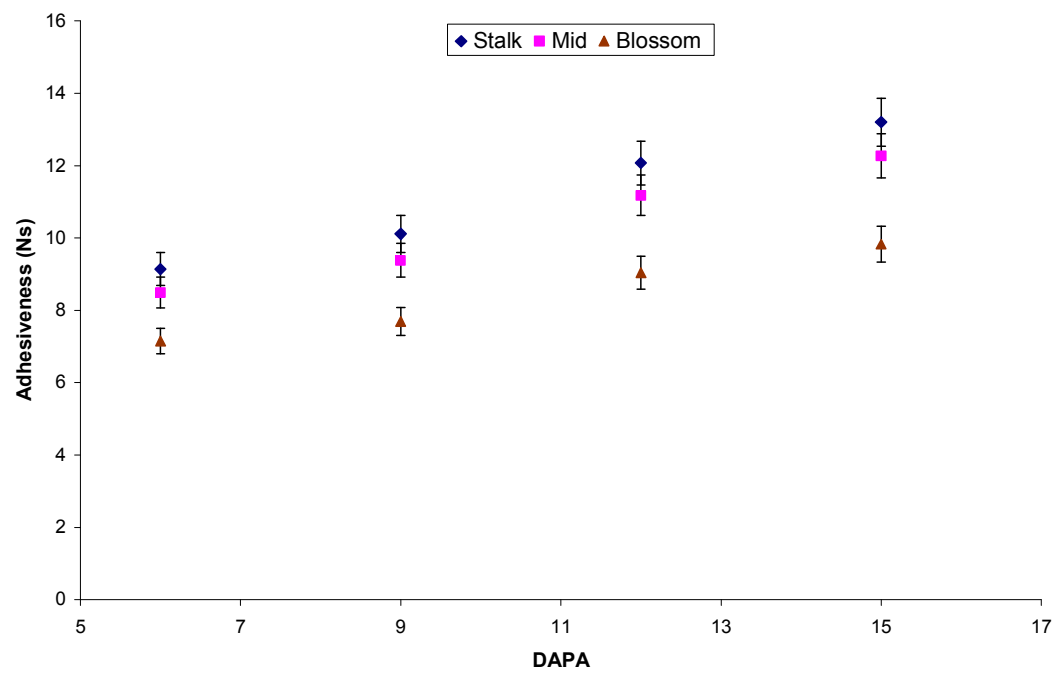

Figure 6. Effect of fruit part and maturity stage on the adhesiveness of Nandini cucumber fruit.

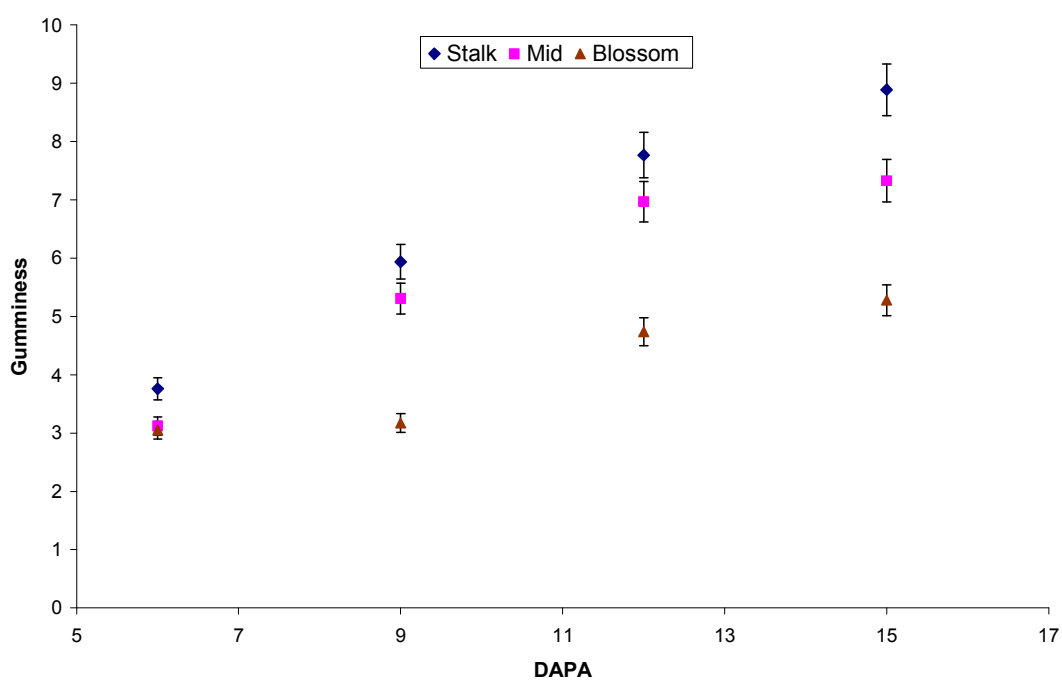

Figure 7. Effect of fruit part and maturity stage on the gumminess of Nandini cucumber fruit. 


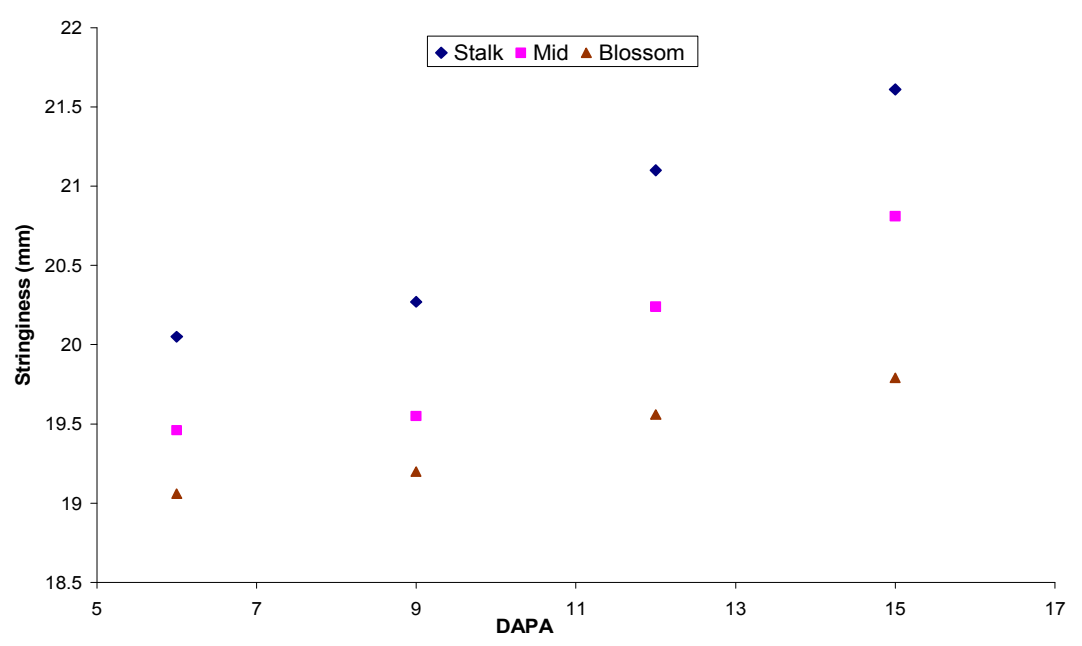

Figure 8. Effect of fruit part and maturity stage on the stringiness of Nandini cucumber fruit.

The regression equations of maturity stage as a function of TPA parameters of Nandini cucumber fruit, with their respective coefficient of determination $\left(\mathrm{R}^{2}\right)$ and correlation (r) were given in Table 2. The regression equations established a strong correlation $(\geq \pm 0.90)$ between the TPA parameters, Nandini fruit part and maturity stage of the fruit. In addition, it can seem that all the TPA parameters increased linearly with increasing maturation stage of the fruit (Figures 2 to 8 ); and could be ascribed to the changes of the fruit textural structures as it matures.

Table 2. Regression analysis of the effect of fruit part and maturity stage on the Textural parameters of Nandini cucumber fruit.

\begin{tabular}{|c|c|c|c|c|c|c|}
\hline Parameter & Part & Linear & $\mathbf{R}^{2}$ & Power function & $\mathbf{R}^{2}$ & $\mathbf{R}$ \\
\hline \multirow[t]{3}{*}{ Hardness $(\mathrm{N})$} & Stalk & $y=3.3413 x+71.221$ & 0.987 & $y=51.12 x^{0.3164}$ & 0.999 & 0.993 \\
\hline & Mid & $y=3.143 x+67.161$ & 0.981 & $y=48.46 x^{0.3138}$ & 0.988 & 0.990 \\
\hline & Blossom & $y=3.3353 x+45.299$ & 0.969 & $y=29.683 x^{0.429}$ & 0.991 & 0.984 \\
\hline \multirow[t]{3}{*}{ Fracturability (N) } & Stalk & $y=3.1163 x+71.896$ & 0.979 & $y=52.404 x^{0.2989}$ & 0.989 & 0.989 \\
\hline & Mid & $y=2.986 x+65.757$ & 0.985 & $\mathrm{y}=47.905 \mathrm{x}^{0.3054}$ & 0.987 & 0.992 \\
\hline & Blossom & $y=3.1187 x+45.324$ & 0.968 & $y=30.074 x^{0.4113}$ & 0.991 & 0.984 \\
\hline \multirow[t]{2}{*}{ Springiness (mm) } & Stalk & $y=0.0067 x+0.83$ & 1.000 & $y=0.7627 x^{0.072}$ & 0.984 & 1.000 \\
\hline & Blossom & $y=0.0053 x+0.724$ & 0.914 & $y=0.6736 x^{0.0637}$ & 0.842 & 0.956 \\
\hline \multirow[t]{3}{*}{ Chewiness $(\mathrm{Nm})$} & Stalk & $y=0.5593 x+0.057$ & 0.972 & $y=0.5063 x^{1.0457}$ & 0.983 & 0.985 \\
\hline & Mid & $y=0.492 x-0.086$ & 0.970 & $y=0.3774 x^{1.1037}$ & 0.973 & 0.984 \\
\hline & Blossom & $y=0.233 x+0.716$ & 0.956 & $y=0.5724 x^{0.7303}$ & 0.939 & 0.977 \\
\hline \multirow[t]{3}{*}{ Adhesiveness (Ns) } & Stalk & $y=0.4713 x+6.181$ & 0.983 & $\mathrm{y}=4.2579 \mathrm{x}^{0.4141}$ & 0.966 & 0.991 \\
\hline & Mid & $y=0.438 x+5.731$ & 0.983 & $\mathrm{y}=3.9543 \mathrm{x}^{0.4138}$ & 0.965 & 0.991 \\
\hline & Blossom & $y=0.313 x+5.141$ & 0.975 & $y=3.6662 x^{0.3591}$ & 0.949 & 0.987 \\
\hline \multirow[t]{2}{*}{ Gumminess (N) } & Stalk & $y=0.574 x+0.563$ & 0.981 & $y=0.7026 x^{0.9533}$ & 0.987 & 0.990 \\
\hline & Blossom & $y=0.2753 x+1.169$ & 0.907 & $y=0.8829 x^{0.6521}$ & 0.857 & 0.952 \\
\hline \multirow[t]{3}{*}{ Stringiness (mm) } & Stalk & $y=0.1837 x+18.829$ & 0.959 & $y=17.103 x^{0.0842}$ & 0.909 & 0.979 \\
\hline & Mid & $y=0.158 x+18.356$ & 0.931 & $y=16.888 x^{0.0738}$ & 0.857 & 0.964 \\
\hline & Blossom & $y=0.085 x+18.51$ & 0.975 & $y=17.62 x^{0.0419}$ & 0.935 & 0.987 \\
\hline
\end{tabular}

Where $y=$ the textural parameter; $x=$ maturity stage

\section{Conclusions}

The results of the study showed that the fruit part and maturity stage significantly influenced all the textural qualities of the Nandini cucumber fruit. The results indicated that the fruit hardness, springiness, gumminess, stringiness, fracturability, adhesiveness and chewiness decreased from the stalk part of the fruit to the blossom part. All the parameters studied increased with increase in maturation for 6 DAPA to 15 DAPA; and strong correlation $(\geq \pm 0.90)$ was established between the TPA parameters and maturity stage.

\section{References}

[1] Ullah, M. Z., Hassan, M. J., Chowdhury, A. Z. M. K. A, Saki, A. I. and Rahman, A. H. M. A. (2012). Genetic variability and correlation in exotic cucumber (Cucumis sativus L.) varieties. Bangladesh Journal of Plant Breeding and Genetics 25(1):1723.

[2] Eboibi, O. and Uguru, H. (2017). Storage conditions effect on physical, mechanical and textural properties of intact cucumber (cv Nandini). International Journal of Engineering and Technical Research. Volume-7, Pp 48-56 
[3] Eboibi, O. and Uguru, H. (2018). Effect of Moisture Content on the Mechanical Properties of Cucumber Fruit. International Journal of Scientific \& Engineering Research Volume 9, pp 671-678.

[4] Nema, N. K., Maity, N., Sarkar, B. and Mukherjee, P. K. (2011). Cucumis sativus fruit potential antioxidant, antihyaluronidase, and anti-elastase agent. Archives of Dermatological Research 303:247-52.

[5] Soni, R. (2017). "8 Amazing Health Benefits of Cucumber Seeds." Downloaded from https://www.homesogood.com/8amazing-health-benefits-of-cucumber-seeds/ downloaded on 24th August, 2017

[6] Bourne M. C. (1980). Texture evaluation of horticultural crops. Hort. Sci., 15, 51-56.

[7] Szczesniak, A. S. (1963). Classification of Textural Characteristics. Journal of Food Science 28.4

[8] Chen, L. and Opara, U. L. (2013). Texture measurement approaches in fresh and processed foods - A review. Food Research International Vol 51 (2): pp 823-835.

[9] Klima, J. L., Malladi, A., Scott, N. D. (2011). Differences in cell number facilitate fruit size variation in Rabbit eye blueberry genotypes. Journal of the American Society for Horticultural Science 136, 10-15.

[10] Costa, F., Cappellin, L., Longhi, S., Guerra, W., Magnano, P., Porro, D., Soukoulis, C., Salvi, S., Velasco, R., Biasioli, F., Gasperi, F. (2011). Assessment of apple (Malus $\times$ domestica Borkh.) fruit texture by a combined acoustic-mechanical profiling strategy. Postharvest Biology and Technology 6, 2128.

[11] Giongo, L., Poncetta, P., Loretti, P., Costa, F., 2013. Texture profiling of blueberries (Vaccinium spp.) during fruit development, ripening and storage. Postharvest Biology and Technology 76 (2013) 34-39.

[12] Alamar, M. C., Vanstreels, E., Oey, M. L., Moltó, E. and Nicolaï, B. M. (2008) Micromechanical behaviour of apple tissue in tensile and compression tests: Storage conditions and cultivar effect. Journal of Food Engineering. 86 (3), 324-333.
[13] Szczesniak A. S., 1998. Effect of storage on texture. In: Food Storage stability (Eds I. A. Taub, R. P. Singh). CRC Press, Boca Raton, FL, USA.

[14] Myhara R. M., Al-Alawi A., Karkalas J. and Taylor M. S. (2000) Sensory and textural changes in maturating Omani dates. Journal of the Science of Food and Agriculture, 80, pp. 2181-2185.

[15] Guiné, R. P. F., Andrade, S. Correia, A. C., Jordão, A. M., Lopes, A. D. and Ferreira, D. (2011). Evaluation of textural properties in apples of regional varieties. International Journal of Food Properties. 14, (2): 331-338.

[16] Paoletti, F., Moneta, E., Bertone, A. and Sinesio, F. (1993). Mechanical Properties and sensory evaluation of selected apple cultivars. Lebensmittel-Wissenschaft und-Technologie (LWT), 26 (3), 264-270.

[17] Mavroudis, N. E., Dejmek, P. and Sjoholm, I. (2004). Studies on some raw material characteristics in different Swedish apple varieties. Journal of Food Engineering. 121-129.

[18] Steffe, J. F. (1996). Rheological Methods in Food Process Engineering. (Second Edition). Freeman Press, USA. Pp 7290 .

[19] Karaj, S. and Muller, J. (2010). Determination of physical, mechanical and chemical properties of seeds and kernels of Jatropha curcas L. Ind. Crop Prod. 32, 129-138.

[20] Brennan, J. G., Jowitt, R. and Mohamed, A. M. A. (1977). Instrumental measurement of fruit texture: a study on apples. Ann. Appl. Biol. 87:121-127.

[21] Abdullah, M. A., Hussain M. S., Diaeldein, O. A. and Mahmoud, A. Y. (2014). Texture profile analysis of date flesh for some Saudi date cultivars. International Journal of General Engineering and Technology. Vol. 3 (3): 1-10.

[22] Nadeem, M., Salim-Rehman, Anjum, F. M., Bhatti, I. A. (2011). Quality evaluation of some Pakistani date varieties, Pakistan. J. Agric. Sci. 48, 305-313. 